\title{
Properties of Kaolinite as a Raw Material for Porcelain
}

\author{
Jong-Young Kim $\mathbb{B}^{\dagger}$ and Kwang-Taek Hwang \\ Icheon branch, Korea Institute of Ceramic Engineering and Technology, Icheon 17303, Korea \\ (Received September 18, 2019; Revised October 8, 2019; Accepted October 10, 2019)
}

\begin{abstract}
In this work, we investigated kaolinite raw materials from China, Vietnam, and Seongju (Korea) used for the manufacture of porcelain products in Korea. According to chemical analysis results, for the kaolinites from Seongju, more feldspar components containing $\mathrm{CaO}, \mathrm{K}_{2} \mathrm{O}$, and $\mathrm{Na}_{2} \mathrm{O}$ are found than in those from China or Vietnam, of which the composition is close to that of pure kaolinite. Through X-ray Rietveld quantitative analysis, kaolinite and muscovite are found to be the main phases for all the raw materials. Halloysite, quartz, gibbsite, and andesine are found at more than 5\% for KM-85 (China), LKC-60 (Vietnam), KC-009 (China), and WA (Seongju). Absorption rate is on order of LKC-60 < KC-009 < KM-85 < PA < WA, and the sample, sintered in reductive atmosphere, exhibits the lowest absorption rate. Comparing the color of the sintered samples, kaolinites of KM-85, LKC-60, and KC-009 (L*: 94 - 97\%) show higher whiteness value than those of WA and PA (L*: 82 - 91\%).
\end{abstract}

Key words : Porcelain, Sintering

\section{Introduction}

$S$ oji, the material directly used in the manufacturing of porcelain products, is prepared with minerals obtained from nature. Therefore, stable quality of the minerals (raw ore) is necessary for stable quality of soji. Unfortunately, however, the mineral resources for porcelain soji, especially the essential minerals such as kaolinite, have already been exhausted in Korea, and most of the materials are imported from other countries. In addition, the porcelain soji products obtained from the manufacturers often deviate from the specifications for the representative quality items, including water content, shrinkage rate, particle size, chromaticity and component analysis, and the quality of soji products is dependent upon the production lot. ${ }^{1)}$

These defects are mostly due to the change of the raw minerals or the absence of specification management. A statistical analysis of the quality of each lot of the soji products manufactured by the porcelain soji manufacturers in terms of the key quality items (water content, shrinkage rate, particle size, chromaticity and component analysis) showed that the percent defective is seriously high and the variance is severe, usually at the points where the raw materials are changed. Therefore, stabilization of the raw minerals is considered essential for stabilization of the soji quality, and thus the stabilization of the properties of the raw minerals is urgently needed. The present study was conducted to

${ }^{\dagger}$ Corresponding author : Jong-Young Kim

E-mail : jykim@kicet.re.kr

Tel : +82-31-645-1423 Fax : +82-31-645-1486

ORCID

https://orcid.org/0000-0001-9302-0040 evaluate the quality of the kaolinite mineral, which is one of the raw materials for porcelain soji products, and the various properties of the porcelain soji prepared by using the kaolinite were evaluated in terms of shrinkage rate, absorption rate, particle size, chromaticity after sintering, component analysis, XRD phase analysis, and microstructure analysis to compare and evaluate the basic properties as a raw material for porcelain soji products.

The expression "kaolinite" according to the current Korean Mining Industry Act includes kaolinite, acid bentonite, bentonite, pottery stone, alumina shale, and clay (kibushi clay and gairome clay). However, the present study was conducted with kaolinite only. Among the porcelain kaolinite materials circulated in the Korean market, the product from Seongju, Gyeongbuk was employed in this study. Mineralogic studies on the kaolinite deposits in Korea have been steadily conducted on the halloysite deposit preserved mainly in the Sancheong-Hadong area, whereas the kaolinite deposits in the Hapcheon, Goryeong, and Seongju areas have been studied less. ${ }^{2)}$

In the Sancheong area where the kaolinite mines are located, anorthosite and leucocratic gabbro, the alkaline masses located along the Sancheong-Hadong area, are found, and gabbro is also found in some parts of the area. A considerable amount of kaolinite, especially high-grade kaolinite, was mined in this area by large-scale mining performed in the past. On the contrary, the kaolinite deposits in Seongju and Hapcheon areas show reserve patterns and production states that are different from those of the kaolinite deposits in the Sancheong-Hadong area, which are well known as weathering residual deposits. The kaolinite deposits in Seongju and Hapcheon areas are known as acidic igneous rocks containing a large portion of felspar, which 
Table 1. Raw Materials and Mine Information

\begin{tabular}{cccc}
\hline No. & name & Country & Region \\
\hline 1 & KM-85 & Vietnam & Phu Tho province \\
2 & LKC-60 & China & Fujian province \\
3 & KC-009 & China & Yunnam province \\
4 & Seongju (WA) & Korea & Seongju-gun \\
5 & Seongju (PA) & Korea & Seongju-gun \\
\hline
\end{tabular}

are usually formed by the weathering or hydrothermal metamorphism of granite rocks. The kaolinite in that area is produced locally without a distinctive association with the development patterns of the topography or ground surface, and downward and deepening metamorphisms are often found. In addition, three other kaolinite products that are imported from Vietnam and China and circulated in the Korean market were selected for the comparison and evaluation.

\section{Experimental Procedure}

\subsection{Synthesis and Materials}

The process of manufacturing soji by using kaolinite includes the general porcelain soji manufacturing process (Fig. 1). ${ }^{3)}$ Felspar and quartzite were added to prepare the soji, and Table 1 and 2 shows the evaluated materials. Wet ball-milling was performed for $1-3 \mathrm{~h}$ and the resulting slurry was stirred at a high speed to homogeneously mix the kaolinite raw materials. An iron-removing process (5,000 G) was then carried out to eliminate the iron contained in the raw materials. The slurry was continuously stirred by using a low-speed stirrer to minimize precipitation, and then transported to a filter press to be prepared in the form of cakes. The cakes then underwent aging for several days and de-aired by auger machine to be prepared as soji. After being dried for $24 \mathrm{~h}$ at room temperature, the shaped products were heated in a $0.3 \mathrm{~m}^{3}$ electric furnace at a rate of $3^{\circ} \mathrm{C} /$ min and kept at a high temperature $\left(1200^{\circ} \mathrm{C} / 1250^{\circ} \mathrm{C}\right)$ for 60 $\mathrm{m}$. The sintering was performed in an atmosphere of $\mathrm{CO}$ $2.0 \%$ controlled by using liquid petroleum gas (LPG) in an electric reducing kiln or in an oxidizing atmosphere (air).

\subsection{Characterization}

A chemical composition analysis was performed with the specimens prepared in powder form by completely drying the raw materials. Inductively Coupled Plasma Optical Emission Spectrometry (ICP-OES, Optima 5300DV, Perkin Elmer) was used for the measurement, where the ICP-OES was used for qualitative and quantitative analyses by mea-

Table 2. Composition of Soji

\begin{tabular}{cccc}
\hline Materials & Kaolinite & $\begin{array}{c}\text { Feldspar } \\
\text { (Buyeo) }\end{array}$ & $\begin{array}{c}\text { Quartz } \\
\text { (Australian) }\end{array}$ \\
\hline ratio (\%) & 46.3 & 18.9 & 34.8 \\
\hline
\end{tabular}

suring the light emitted by atoms or ions in the excited state. The particle size was measured by laser diffraction analysis (Beckman Coulter LS13 320, U.S.A). The samples were prepared by putting about $0.5 \mathrm{~g}$ of the raw materials into a $100 \mathrm{ml}$ vial, adding $0.01 \mathrm{~g}$ of a dispersing agent (CF44), and dispersing the mixture by sonication for $30 \mathrm{~s}$. The XRD crystal phase was analyzed by X-ray diffraction (XRD, Right D/max 2500 v/pc, Rigaku, Japan). The microstructure after the sintering was observed by using a scanning electron microscope (SEM, JSM-6390, JEOL, Japan).

The shrinkage rate of the sintered bodies was measured by marking a $10 \mathrm{~cm}$ long shrinkage checking line in the longitudinal direction of the specimens, drying the specimens at room temperature, and then measuring the length of the shrinkage checking line on the specimens to $0.01 \mathrm{~mm}$ by using digital vernier calipers. The measurement values were converted into the shrinkage rate by comparing the length before and after the sintering. The absorption rate was measured by Archimedes method.

\section{Results and Discussion}

\subsection{Chemical Analysis Results}

Kaolinite, represented by the chemical formula of $\mathrm{Al}_{2} \mathrm{O}_{3} \cdot 2$ $\mathrm{SiO}_{2} \cdot 2 \mathrm{H}_{2} \mathrm{O}$, is one of the important clay minerals, and theoretically contains $\mathrm{SiO}_{2} 46.54 \%, \mathrm{Al}_{2} \mathrm{O}_{3} 39.50 \%$, and $\mathrm{H}_{2} \mathrm{O}$ $13.96 \%$. The kaolinite produced in Korea is known as halloysite kaolinite with the best quality in the world, and most of the kaolinite products have a composition close to the theoretical composition. However, while the imported kaolinite products showed a composition similar to the theoretical

Table 3. Results of Chemical Analysis

\begin{tabular}{|c|c|c|c|c|c|}
\hline $\begin{array}{c}\text { Materials } \\
\text { Element } \\
(\%)\end{array}$ & KM-85 & LKC-60 & KC-009 & $\begin{array}{l}\text { Seongju } \\
\text { (WA) }\end{array}$ & $\begin{array}{c}\text { Seongju } \\
\text { (PA) }\end{array}$ \\
\hline $\mathrm{SiO}_{2}$ & 47.6 & 49.4 & 47.8 & 48.4 & 45.4 \\
\hline $\mathrm{Al}_{2} \mathrm{O}_{3}$ & 36.8 & 35.4 & 36.5 & 34 & 37.7 \\
\hline $\mathrm{Fe}_{2} \mathrm{O}_{3}$ & 0.39 & 0.39 & 0.47 & 1.06 & 1.24 \\
\hline $\mathrm{CaO}$ & 0.07 & 0.09 & 0.09 & 4.67 & 0.2 \\
\hline $\mathrm{MgO}$ & 0.05 & 0.22 & 0.02 & 0.22 & 0.18 \\
\hline $\mathrm{K}_{2} \mathrm{O}$ & 1.13 & 2.51 & 0.81 & 0.51 & 0.33 \\
\hline $\mathrm{Na}_{2} \mathrm{O}$ & 0.44 & 0.32 & 0.71 & 1.7 & 0.45 \\
\hline $\mathrm{TiO}_{2}$ & 0.02 & 0.01 & 0.01 & 0.08 & 0.17 \\
\hline $\mathrm{MnO}$ & 0.03 & 0.02 & $<0.01$ & 0.01 & 0.02 \\
\hline $\mathrm{P}_{2} \mathrm{O}_{5}$ & 0.04 & 0.19 & 0.15 & $<0.01$ & - \\
\hline $\mathrm{ZrO}_{2}$ & $<0.01$ & 0.02 & $<0.01$ & $<0.01$ & $<0.01$ \\
\hline $\mathrm{Li}_{2} \mathrm{O}$ & $<0.01$ & $<0.01$ & $<0.01$ & $<0.01$ & $<0.01$ \\
\hline $\mathrm{SrO}$ & $<0.01$ & $<0.01$ & $<0.01$ & 0.04 & 0.01 \\
\hline $\mathrm{ZnO}$ & 0.01 & $<0.01$ & - & 0.01 & 0.01 \\
\hline $\mathrm{Cr}_{2} \mathrm{O}_{3}$ & $<0.01$ & $<0.01$ & $<0.01$ & - & $<0.01$ \\
\hline $\mathrm{BaO}$ & 0.01 & - & - & 0.02 & - \\
\hline Ig. Loss & 13.3 & 11.4 & 13.4 & 10.75 & 14.2 \\
\hline
\end{tabular}



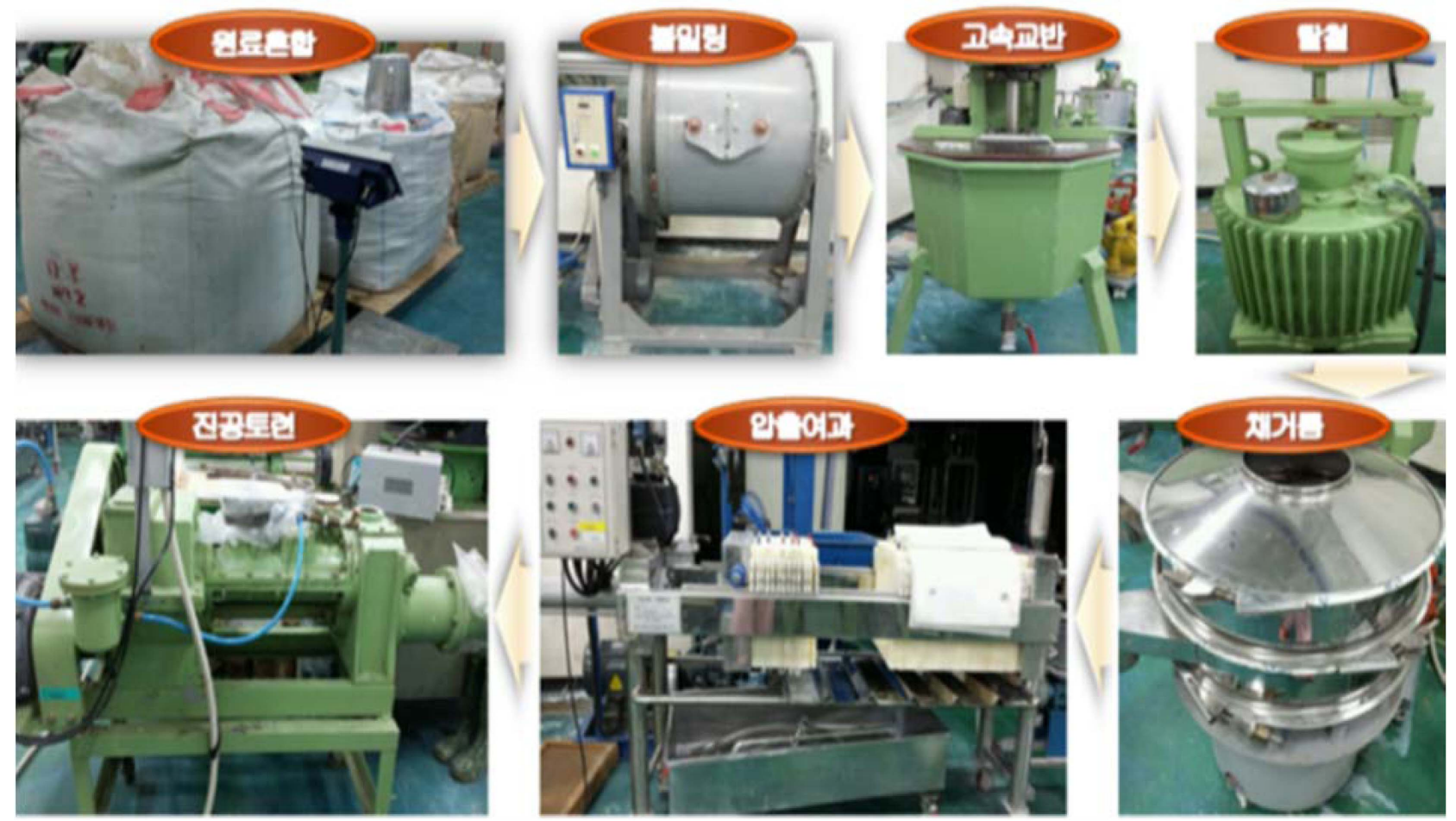

Fig. 1. Manufacture process of Soji from Kaolinite.

composition, the Korean kaolinite analyzed in the present study showed $\mathrm{SiO}_{2}$ content of $45 \%$ to $48 \%$, and $\mathrm{Al}_{2} \mathrm{O}_{3}$ content of $33 \%$ to $36 \%$, indicating that the $\mathrm{Al}_{2} \mathrm{O}_{3}$ content was lower than the theoretical value by $3 \%$ to $6 \%$. Instead, the Korean kaolinite contained as impurities $\mathrm{CaO}$ at $4 \%$ to $5 \%$ and $\mathrm{K}_{2} \mathrm{O}+\mathrm{Na}_{2} \mathrm{O}$ at $2 \%$ to $3 \%$ at relatively high ratios (Table 3 ).

The content of iron $\left(\mathrm{Fe}_{2} \mathrm{O}_{3}\right)$, which determines the color of the kaolinite raw material as well as the color of the porcelain, was generally low at about $1 \%$. The kaolinite products imported from China and Vietnam had an iron content of $0.5 \%$ or less, showing a better whiteness compared to the Korean kaolinite product.

\subsection{X-ray Rietveld Crystal Phase Analysis}

An X-ray Rietveld quantitative analysis was performed to analyze the types of the crystal phase present in the raw material minerals and their relative ratios. The X-ray diffraction patterns obtained from the individual specimens were compared with the Joint Committee Powder Diffraction File (JCPDF) database to identify the types of crystal phases, and a Rietveld quantitative analysis was performed by using the crystal structure information of the ICSD data corresponding to the identified crystal phases (Fig. 2). The area of the diffraction pattern of each crystal phase obtained from the quantitative analysis was calculated, and the cal-

Table 4. Crystallographic Information on Crystalline Phases Used for Rietveld Quantitative Analysis

\begin{tabular}{|c|c|c|c|c|}
\hline $\begin{array}{l}\text { Crystalline } \\
\text { phase }\end{array}$ & Formula & PDF number & ICSD code & $\begin{array}{l}\text { Crystal system } \\
\text { spacegroup }\end{array}$ \\
\hline Quartz & $\mathrm{SiO}_{2}$ & $85-1053$ & 34636 & Hexagonal P3221(154) \\
\hline Kaolinite & $\mathrm{Al}_{2}\left(\mathrm{Si}_{2} \mathrm{O}_{5}\right)(\mathrm{OH})_{4}$ & $89-6538$ & 87771 & $\begin{array}{l}\text { Triclinic } \\
\text { C1 (1) }\end{array}$ \\
\hline Muscovite & $\mathrm{K}_{0.77} \mathrm{Al}_{1.93}\left(\mathrm{Al}_{0.5} \mathrm{Si}_{3.5} \mathrm{O}_{10}\right)(\mathrm{OH})_{2}$ & $70-1869$ & 4368 & $\begin{array}{l}\text { Monoclinic } \\
\text { C2/c (15) }\end{array}$ \\
\hline Andesine & $\mathrm{Na}_{0.622} \mathrm{Ca}_{0.368} \mathrm{Al}_{1.29} \mathrm{Si}_{2.71} \mathrm{O}_{8}$ & $83-1938$ & 100867 & $\begin{array}{l}\text { Triclinic } \\
\text { C-1 (2) }\end{array}$ \\
\hline Gibbsite & $\mathrm{Al}(\mathrm{OH})_{3}$ & $76-1782$ & 36233 & $\begin{array}{l}\text { Monoclinic } \\
\text { P21/n (14) }\end{array}$ \\
\hline Rutile & $\mathrm{TiO}_{2}$ & $89-4202$ & 44881 & $\begin{array}{l}\text { Tetragonal } \\
\text { P42/mnm }\end{array}$ \\
\hline Halloysite & $\mathrm{Si}_{2} \mathrm{Al}_{2} \mathrm{O}_{5}(\mathrm{OH})_{4}$ & $74-1023$ & 26717 & $\begin{array}{l}\text { Monoclinc } \\
\text { Cm (8) }\end{array}$ \\
\hline
\end{tabular}



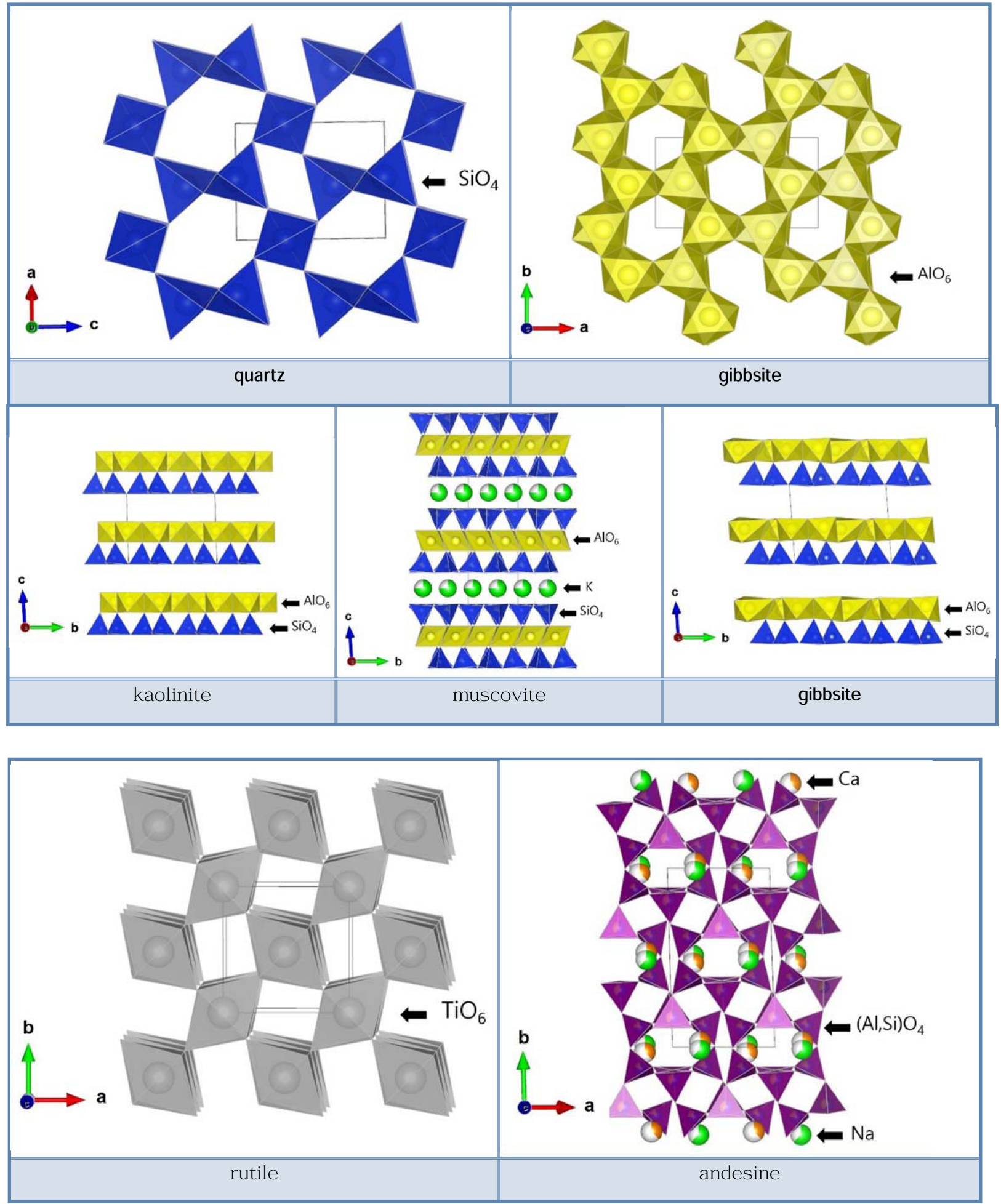

Fig. 2. Structure of crystalline phase used for Rietveld analysis.

culated area was used to calculate the relative ratios of the individual crystal phases. Table 4 shows the information about the material used for the analysis. The measurement was performed by using a Rigaku X-ray diffractometer at $\lambda$ $=1.5418 \AA, 25^{\circ} \mathrm{C}, 40 \mathrm{kV}$ power, and $30 \mathrm{~mA}$ current in the range of $5^{\circ}$ to $80^{\circ}$ for two seconds in each step in an interval of $0.02^{\circ}$.

The Rietveld quantitative analysis was performed for each of the specimens to determine the mass ratios of the phases included in the individual raw materials. ${ }^{4)}$ In the analysis, the positions of the atoms included in each phase were fixed, and only the lattice constant, the preferred ori- 


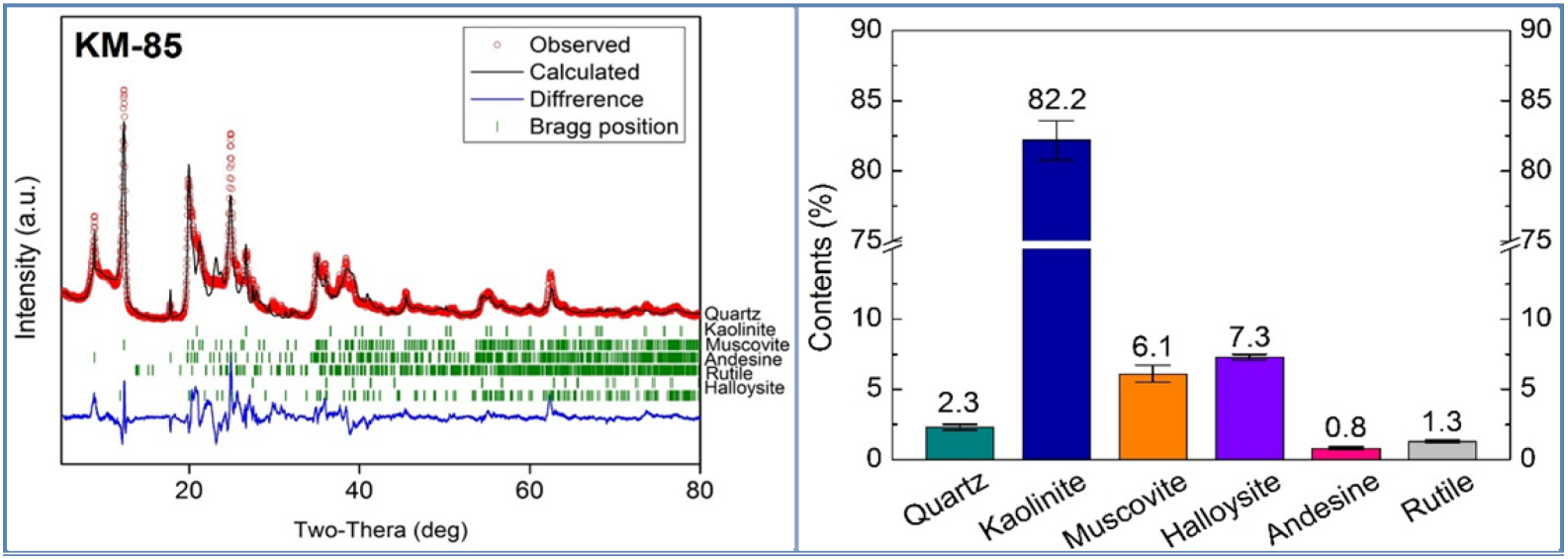

Fig. 3. Rietveld analysis results for KM-85.
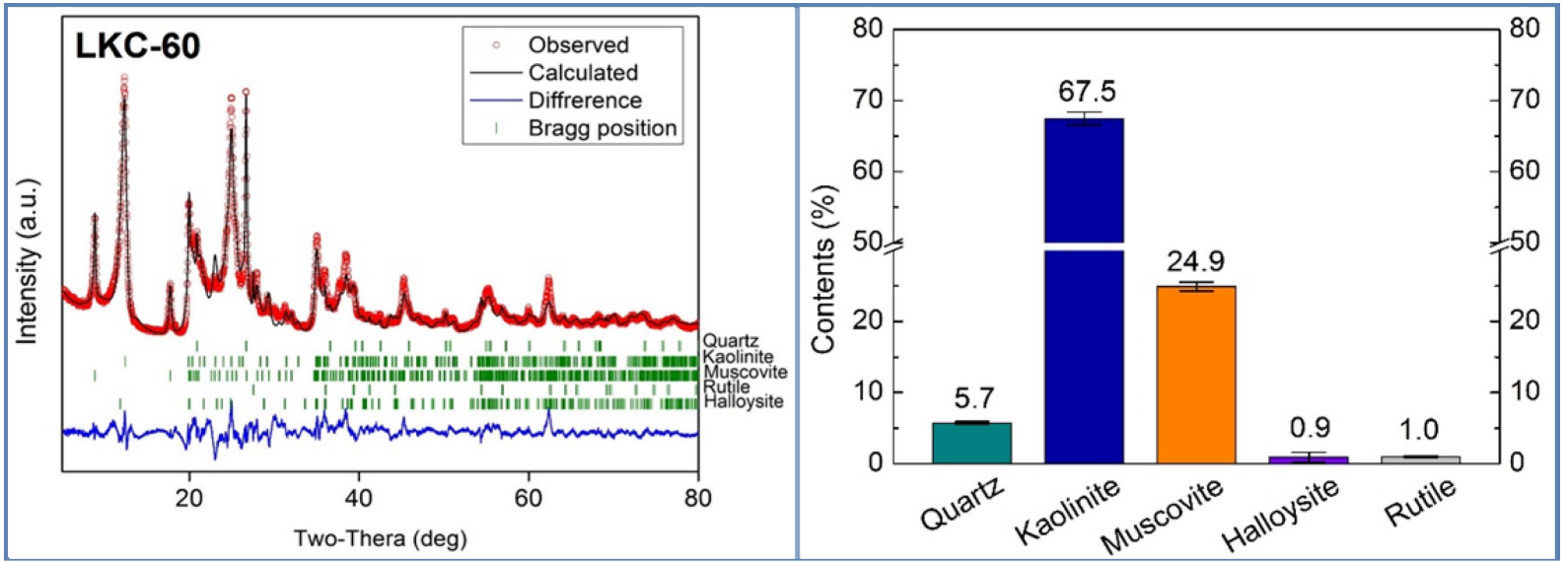

Fig. 4. Rietveld analysis results for LKC-60.
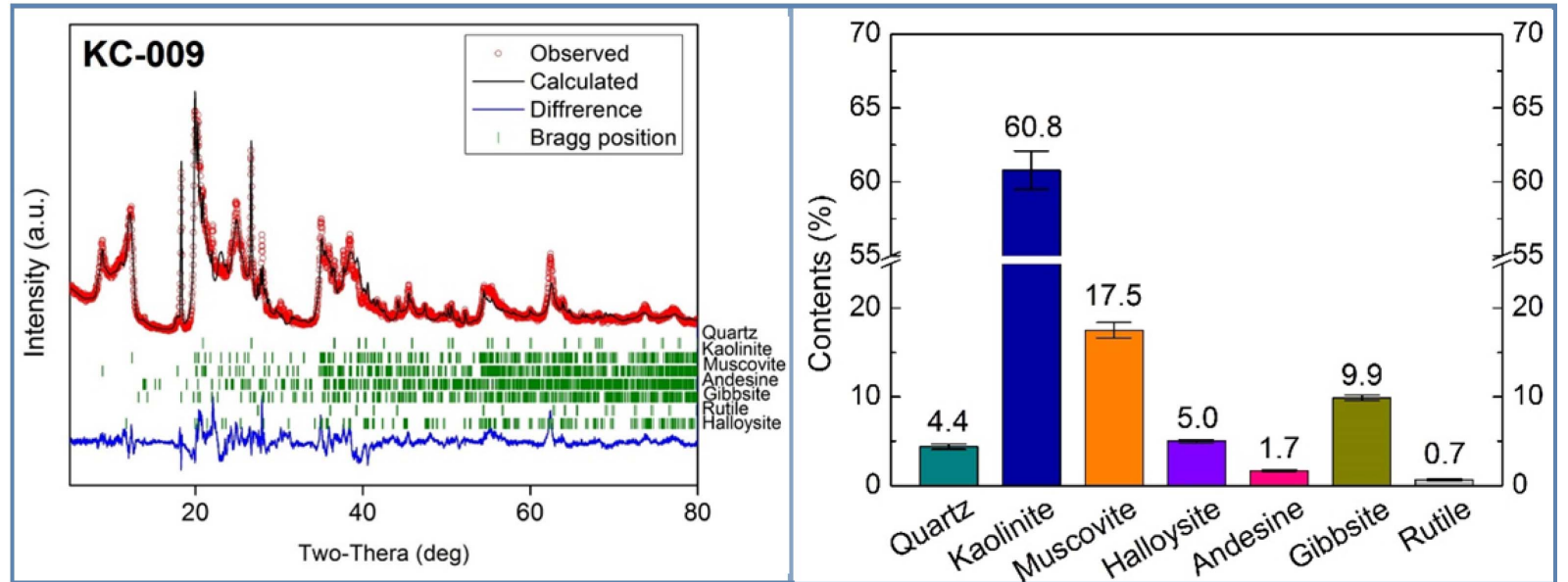

Fig. 5. Rietveld analysis results for KC-009

entation and the overall isotropic thermal parameter were calculated. The analytical results are shown in Figs. 3 to 7 and Table 5 below.

Figures 5 to 7 show the results of the Rietveld analysis. The red dots represent the XRD measurement data, the black lines the calculated values, the green bars the Bragg positions of the individual phases, and the blue lines the differences between the calculated values and the measurement data. The results of the calculation are summarized in Tables 5-6. The Rietveld quantitative analysis showed that 

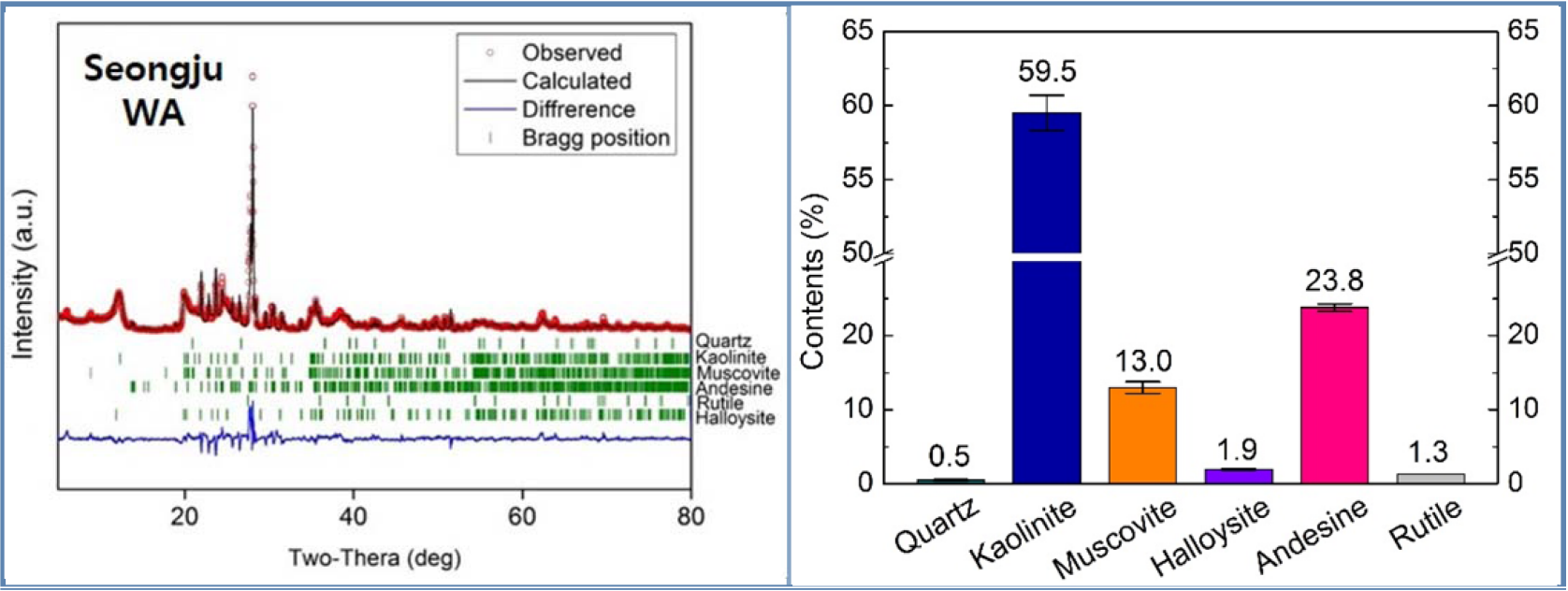

Fig. 6. Rietveld analysis results for Seongju(WA).
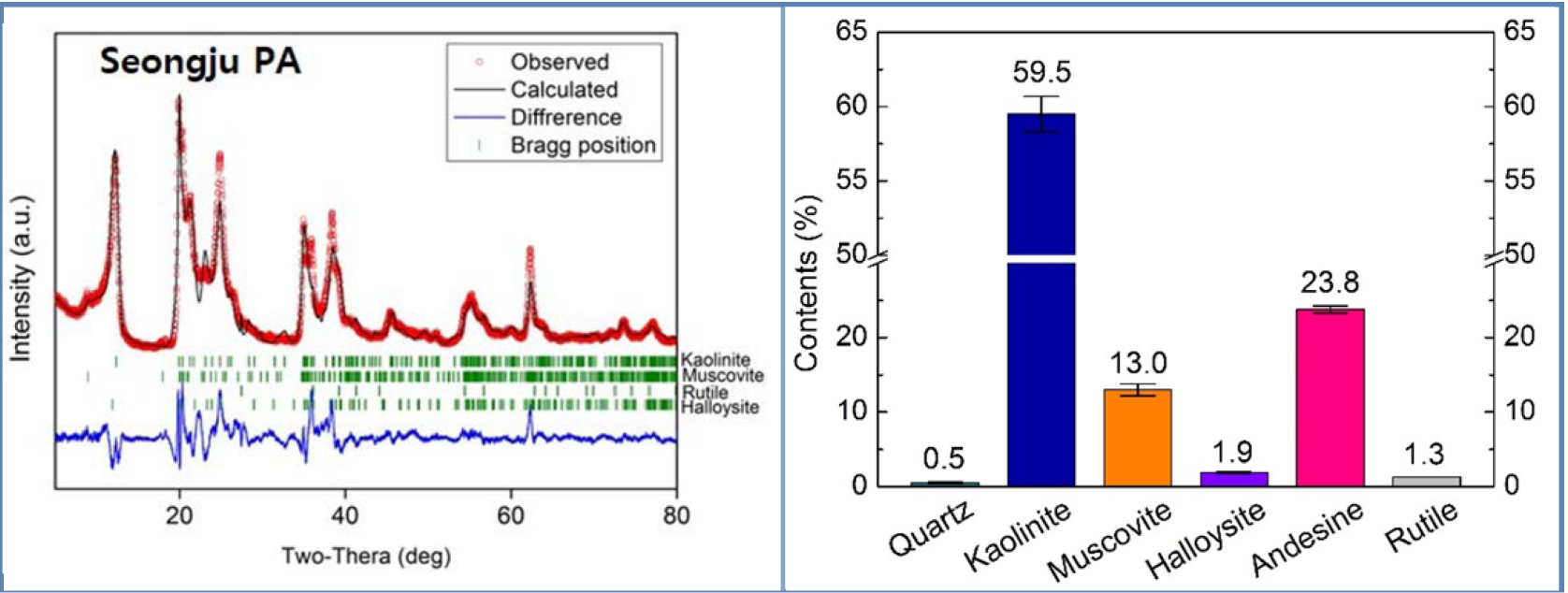

Fig. 7. Rietveld analysis results for Seongju(PA).

kaolinite and muscovite are the main phases in all five raw materials. The content of kaolinite and muscovite, the main phases, was different between the five raw materials. A dis- tinctive difference in the composition was that the KM-85 specimen contained halloysite, the LKC-60 specimen quartz, the KC-009 specimen gibbsite, and the kaolinite WA

Table 5. Quantitative Analysis of Crystalline Phases by X-ray Rietveld Analysis

\begin{tabular}{|c|c|c|c|c|c|c|}
\hline \multicolumn{2}{|c|}{$\begin{array}{c}\text { Materials } \\
\text { Portin (wt.\%) }\end{array}$} & KM-85 & LKC-60 & KC-009 & Seongju (WA) & Seongju (PA) \\
\hline \multicolumn{2}{|c|}{ Quartz } & $2.3(2)$ & $5.7(2)$ & $4.4(3)$ & $0.5(1)$ & - \\
\hline \multicolumn{2}{|c|}{ Kaolinite } & $82.2(14)$ & $67.5(9)$ & $60.8(13)$ & $59.5(12)$ & $89.3(11)$ \\
\hline \multicolumn{2}{|c|}{ Muscovite } & $6.1(6)$ & $24.9(6)$ & $17.5(9)$ & $13.0(8)$ & $8.8(5)$ \\
\hline \multicolumn{2}{|c|}{ Andesine } & $0.8(1)$ & - & $1.7(1)$ & $23.8(5)$ & - \\
\hline \multicolumn{2}{|c|}{ Gibbsite } & - & - & $9.9(3)$ & - & - \\
\hline \multicolumn{2}{|c|}{ Rutile } & $1.3(1)$ & $1.0(1)$ & $0.7(1)$ & $1.3(1)$ & $0.6(1)$ \\
\hline \multicolumn{2}{|c|}{ Halloysite } & $7.3(2)$ & $0.9(7)$ & $5.0(2)$ & $1.9(1)$ & $1.3(2)$ \\
\hline \multirow{4}{*}{$\begin{array}{l}\text { Reliability } \\
\text { factor }\end{array}$} & $\operatorname{Rp}(\%)$ & 13.8 & 10.2 & 9.93 & 11.6 & 11.2 \\
\hline & Rwp (\%) & 18.0 & 13.8 & 13.4 & 15.3 & 14.6 \\
\hline & $\operatorname{Rexp}(\%)$ & 7.67 & 7.67 & 7.65 & 7.96 & 7.70 \\
\hline & $\chi^{2}$ & 5.49 & 3.21 & 3.08 & 3.68 & 3.60 \\
\hline
\end{tabular}


Table 6. Chemical Composition by Quantitative Analysis and by Chemical Analysis

\begin{tabular}{cccccccccc}
\hline Materials & Method & $\mathrm{SiO}_{2}$ & $\mathrm{Al}_{2} \mathrm{O}_{3}$ & $\mathrm{Fe}_{2} \mathrm{O}_{3}$ & $\mathrm{TiO}_{2}$ & $\mathrm{CaO}$ & $\mathrm{Na}_{2} \mathrm{O}$ & $\mathrm{K}_{2} \mathrm{O}$ & $\mathrm{Ig}_{2}$ loss \\
\hline \multirow{2}{*}{ KM-85 } & XRF, ICP & 47.6 & 36.8 & 0.39 & 0.02 & 0.07 & 0.44 & 1.13 & 13.3 \\
& Rietveld & 54.7 & 43.3 & - & 0.4 & 0.1 & $<0.01$ & 1.4 & - \\
\multirow{2}{*}{ LKC-60 } & XRF, ICP & 49.4 & 36.5 & 0.47 & 0.01 & 0.09 & 0.32 & 2.51 & 11.4 \\
& Rietveld & 56.0 & 39.1 & - & 0.3 & $<0.01$ & $<0.01$ & 4.6 & - \\
\multirow{2}{*}{ KC-009 } & XRF, ICP & 47.8 & 36.5 & 0.47 & 0.01 & 0.09 & 0.71 & 2.51 & 13.4 \\
& Rietveld & 51.7 & 44.3 & - & 0.2 & 0.1 & 0.1 & 3.6 & - \\
\multirow{2}{*}{ Seongju WA } & XRF, ICP & 48.4 & 34 & 1.06 & 0.08 & 4.67 & 1.7 & 0.51 & 90.75 \\
& Rietveld & 55.9 & 38.2 & - & 0.4 & 1.4 & 1.3 & 2.8 & - \\
\multirow{2}{*}{ Seongju PA } & XRF, ICP & 45.4 & 37.7 & 1.24 & 0.17 & 0.2 & 0.45 & 0.33 & 14.2 \\
& Rietveld & 54.5 & 43.3 & - & 0.2 & $<0.01$ & $<0.01$ & 1.9 & - \\
\hline
\end{tabular}

Table 7. Particle Size Analysis Results

\begin{tabular}{ccccc}
\hline & $\begin{array}{c}\text { Mean size } \\
(\mu \mathrm{m})\end{array}$ & $\begin{array}{c}\text { D10 } \\
(\mu \mathrm{m})\end{array}$ & $\begin{array}{c}\text { D50 } \\
(\mu \mathrm{m})\end{array}$ & $\begin{array}{c}\text { D90 } \\
(\mu \mathrm{m})\end{array}$ \\
\hline KM-85 & 9.58 & 3.43 & 8.56 & 16.76 \\
LKC-60 & 6.36 & 3.18 & 5.91 & 10.05 \\
KC-009 & 7.53 & 2.21 & 7.11 & 13.10 \\
Seongju (WA) & 23.56 & 4.59 & 11.86 & 60.58 \\
Seongju (PA) & 6.48 & 3.07 & 6.14 & 10.30 \\
\hline
\end{tabular}

andesine, each at a ratio equal to higher than $5 \mathrm{wt} \%$. The Seongju kaolinite specimen mostly contained kaolinite and muscovite only.

\subsection{Particle Size Analysis}

A microstructure of small plates is generally preferred for a soji product to have plasticity. Well dispersed particles having a diameter of $2 \mu \mathrm{m}$ or less are generally referred to as colloidal particles. Having a large surface area, colloidal particles increase the tension of the water surface and thus increase the cohesive force. In addition, colloidal particles play the role of a friction material between coarse particles that reduces the frictional resistance between coarse particles. Therefore, the plasticity is dependent upon the ratio of colloidal particles. Compared to the Vietnamese (KM-85) or Chinese (LKC-60, KC-009) kaolinite specimens, the Korean kaolinite (WA) specimen showed a high ratio of coarse particles having a diameter of $50 \mu \mathrm{m}$ or higher and the cumulative ratio of the smaller particles having a diameter of $2 \mu \mathrm{m}$ or less was low. The particle size distribution shown in Fig. 8 also indicates that the distribution of the Korean kaolinite (WA) specimen was not as uniform as that of the other kaolinite specimens.

\subsection{Microstructure}

A small particle size and a high ratio of small particles
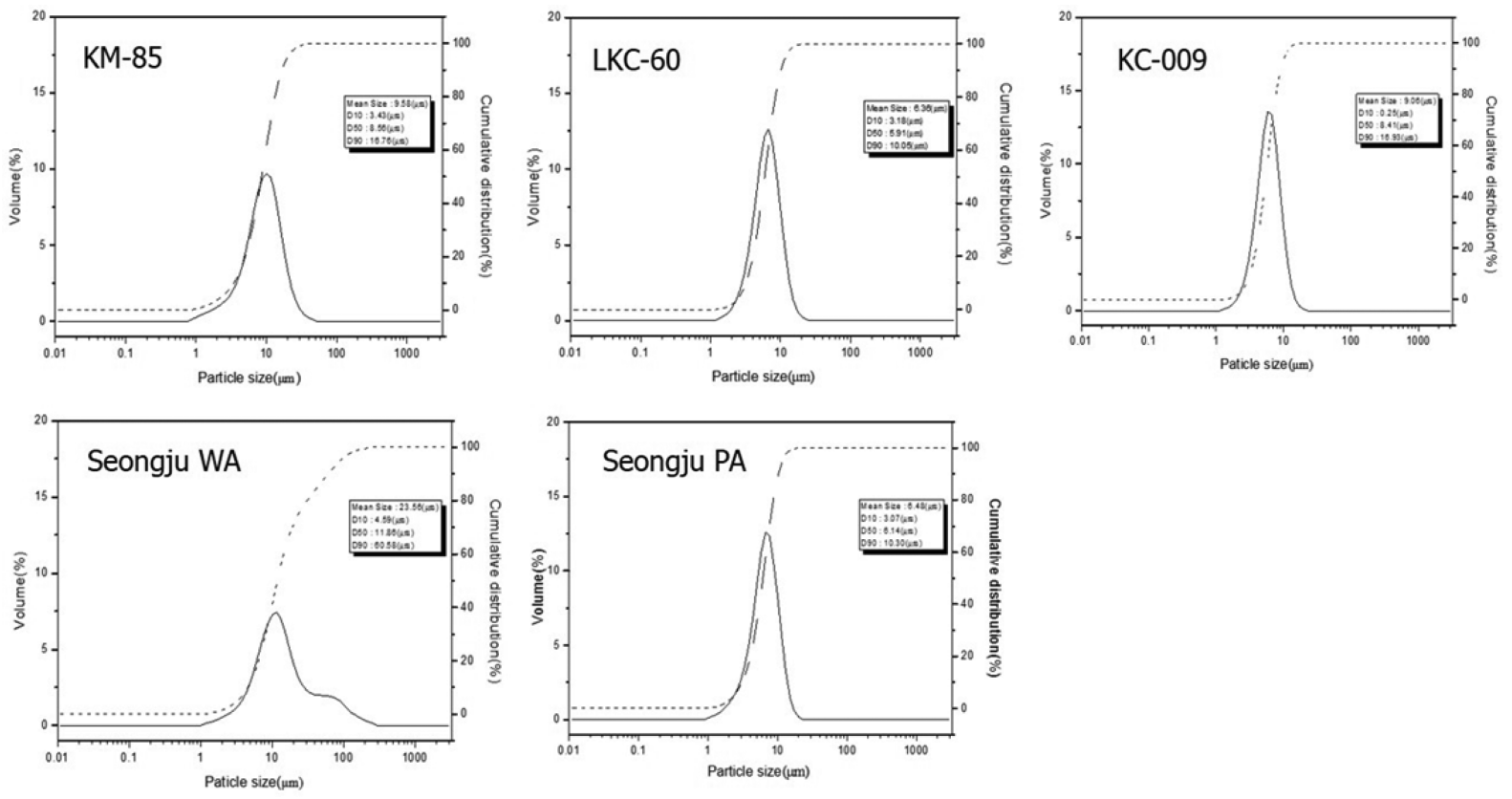

Fig. 8. Particle size analysis of KM-85, LKC-60, KC-009, Seongju(WA), Seongju(PA). 

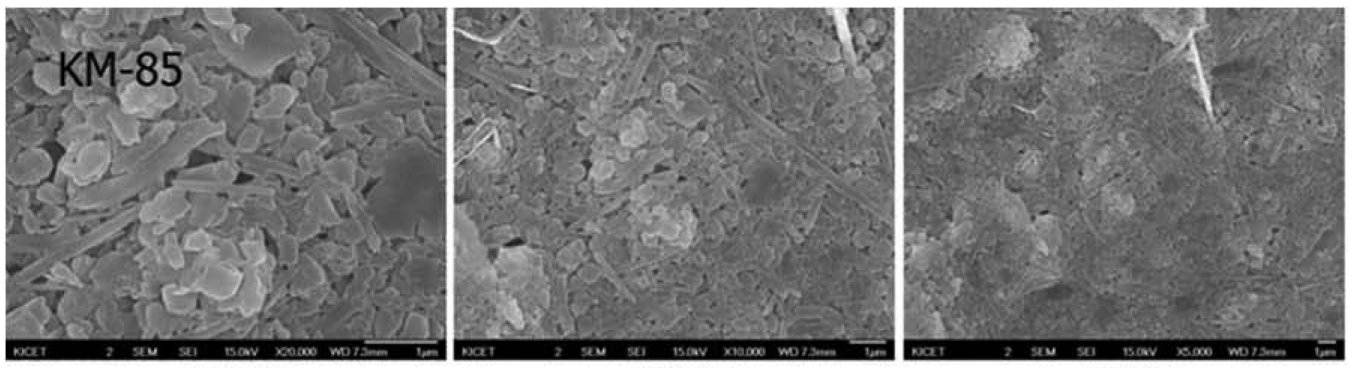

$\times 20000$

x10000

$\times 5000$
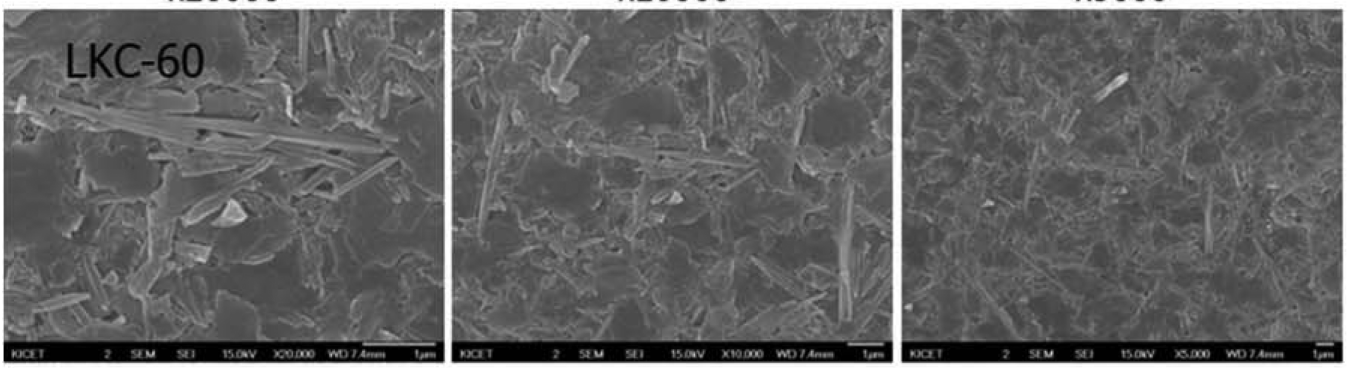

$\times 20000$

$x 10000$

$\times 5000$
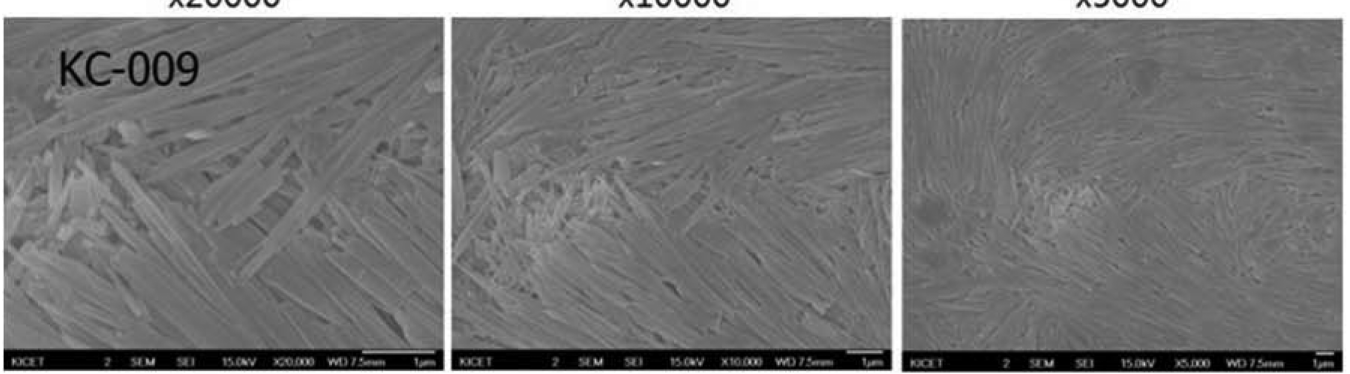

x20000

x10000

x5000
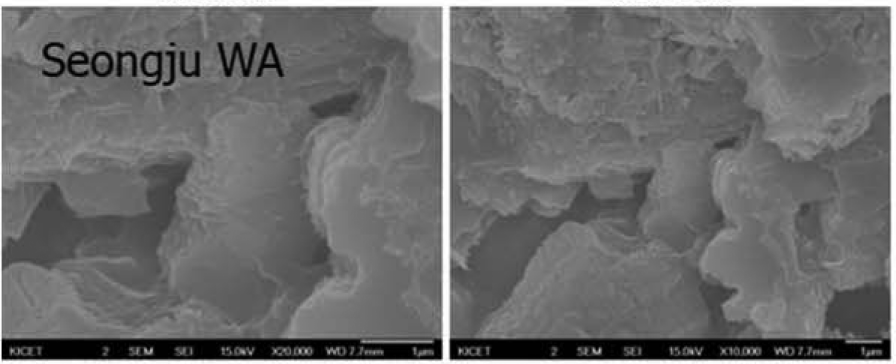

x20000

$x 10000$
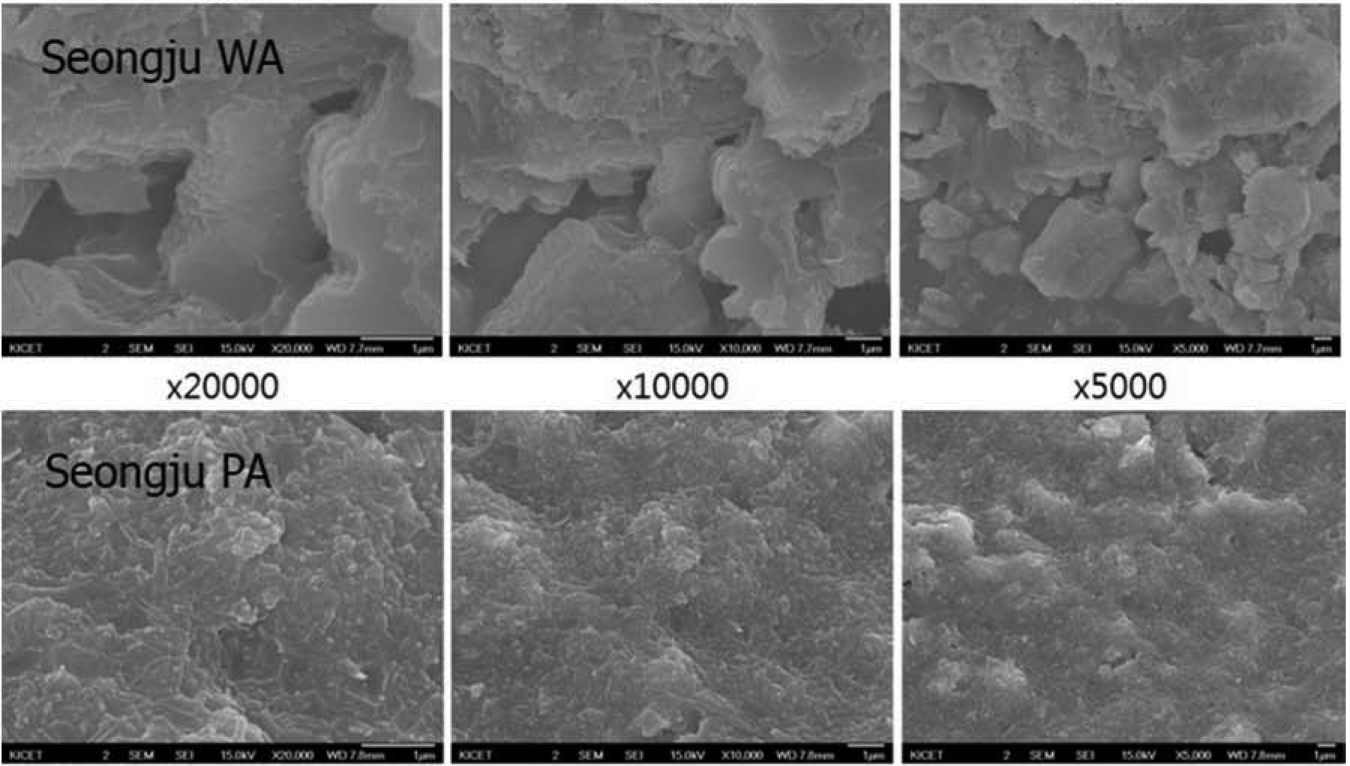

$\times 5000$

$\times 20000$

x10000

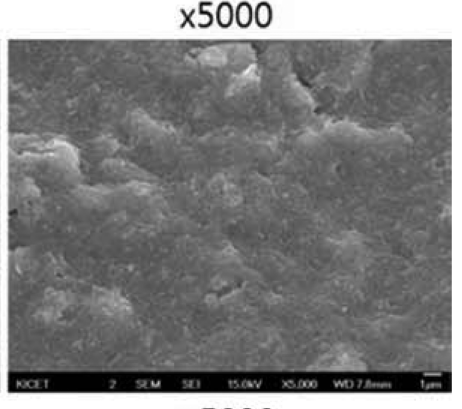

Fig. 9. Microstructure of KM-85, LKC-60, KC-009, Seongju (WA), Seongju (PA).

have a significant effect on the plasticity. In addition, the shape of the small particles also affects the plasticity. As the surface area of particles is increased, the plasticity is increased. The surface area ratio of spherical, planar, and needle-like particles is 3:22:41. As the ratios of planar and needle-like particles, which have a large surface area, are increased, the plasticity is increased. Most of the kaolinite particles in the Vietnamese (KM-85) and Chinese (LKC-60, 
KC-009) specimens were planar and needle-like, and thus a high plasticity was expected (Fig. 9). The fine particles included in the Korean kaolinite specimens (WA and PA) were planar, but the coarse particles were in the shape of lumps similar to that of quartzite. The coarse particles may decrease the plasticity after being prepared as soji.

The effect of particle shape on the plasticity is clearly seen when the particles are prepared as soji and molded. Even if a soji product is prepared by appropriately controlling the ratios of fine particles and coarse and finely grinding the particles with a ball mill, if the particle shape is not appropriately regulated to be planar or needle-like, the lack of cohesive force may cause a problem in the molding. On the contrary, when the planar clay mineral particles are refined by elutriation without damaging the particle shape and the minerals such as kaolinite are finely ground in a planar shape to prepare a soji product, the particles have cohesive force, a high viscosity, and a high plasticity and thus are easily molded. Therefore, the Korean kaolinite minerals should be processed by using a stamp mill to control the particle size and change the particle shape into a planar shape.

\subsection{Absorption Rate and Shrinkage Rate}

The sintered Chinese LKC-60 specimen showed a relatively low absorption rate $(\sim 0.8 \%)$, which may be associated with its high plasticity due to the appropriate mixing of the planar and needle-like particles, as shown by the micro- structure analysis. The absorption rate was in the order of LKC- $60<$ KC-009 < KM-85 < PA < WA. The lowest absorption rate was found in the specimens that were sintered at $1250^{\circ} \mathrm{C}$ in a reducing atmosphere.

The sintering shrinkage rate is associated with the absorption rate measurement. Generally, the two properties are inversely proportional to each other: as the absorption rate is decreased, the shrinkage rate is increased; as the absorption rate is increased, the shrinkage rate is decreased. The imported kaolinite specimens showed a relatively high shrinkage rate of $7 \%$ to $12 \%$. In the case of the Korean WA specimen, the shrinkage was $2 \%$ to $6 \%$ at the sintering temperature of $1200^{\circ} \mathrm{C}$ and $3 \%$ to $7 \%$ at $1250^{\circ} \mathrm{C}$, indicating that the shrinkage rate increased with the increase of the sintering temperature. However, the overall shrinkage rate of the Korean WA specimen was relatively low.

\subsection{Chromaticity}

The whiteness of a sintered body is dependent upon the presence of colored minerals, such as iron oxide, chlorite, and biotite, and the sintering atmosphere. Generally, the whiteness is decreased in the oxidizing atmosphere as the sintering temperature is increased, because the color formation by $\mathrm{Fe}_{2} \mathrm{O}_{3}$ is enhanced by the temperature increase. In contrast, as the sintering temperature is increased in the reducing atmosphere, the whiteness is increased, because $\mathrm{Fe}_{2} \mathrm{O}_{3}$ is reduced to $\mathrm{FeO}{ }^{5-7)}$ The whiteness is the lowest when the sintering is completed. When the temperature is

Table 8. Chromaticity Analysis Results (Sintered in Oxidative Atmosphere)

\begin{tabular}{ccccccccccc}
\hline \multicolumn{1}{c}{$1200^{\circ} \mathrm{C}$ sintering } \\
\hline & KM-85 & LKC-60 & KC-009 & WA & PA & KM-85 & LKC-60 & KC-009 & WA & PA \\
$\mathrm{L}^{*}$ & 94.86 & 95.45 & 97.14 & 91.70 & 90.64 & 94.86 & 94.55 & 97.03 & 92.39 & 91.64 \\
$\mathrm{a}^{*}$ & 1.21 & 0.61 & 0.06 & 1.07 & 2.14 & 0.82 & 0.46 & -0.10 & 0.70 & 1.16 \\
$\mathrm{~b}^{*}$ & 2.87 & 3.84 & 3.94 & 6.69 & 6.40 & 3.03 & 4.65 & 4.27 & 7.07 & 6.83 \\
\hline
\end{tabular}
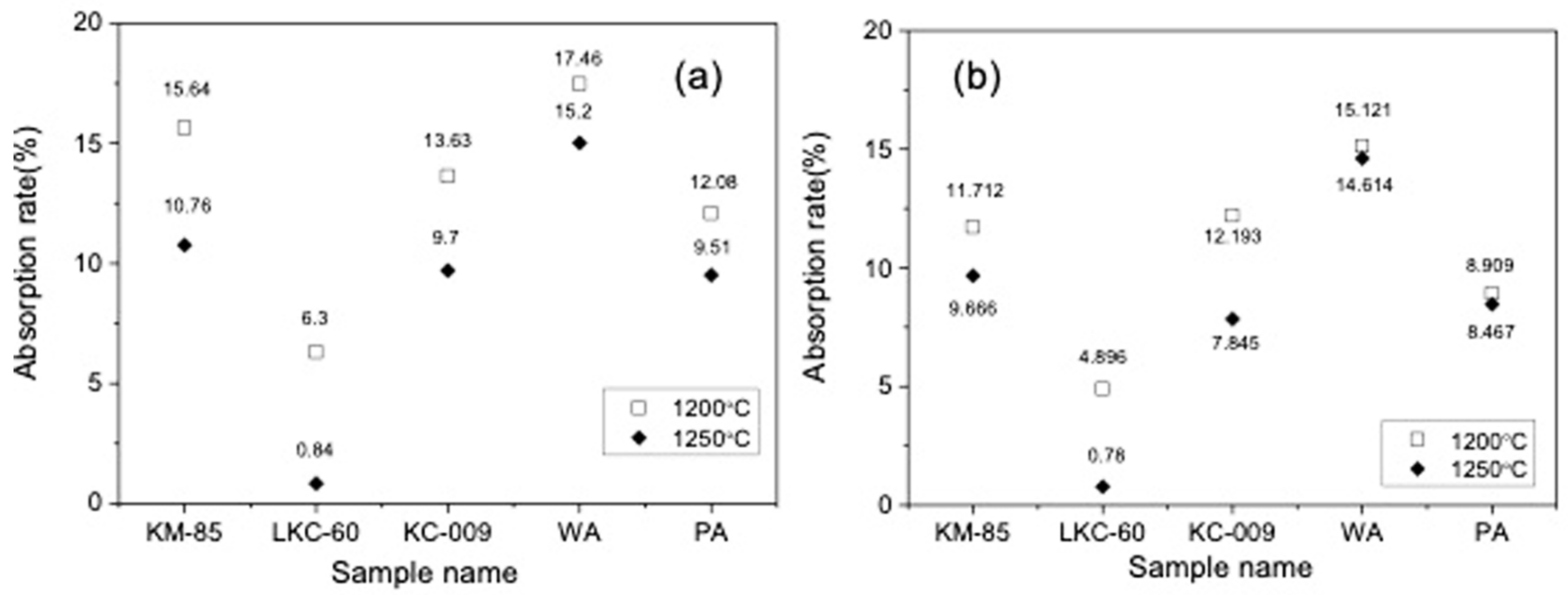

Fig. 10. Absorption rate (a) after oxidative sintering, (b) after reductive sintering; Shrinkage rate (c) after oxidative sintering, (d) after reductive sintering. 

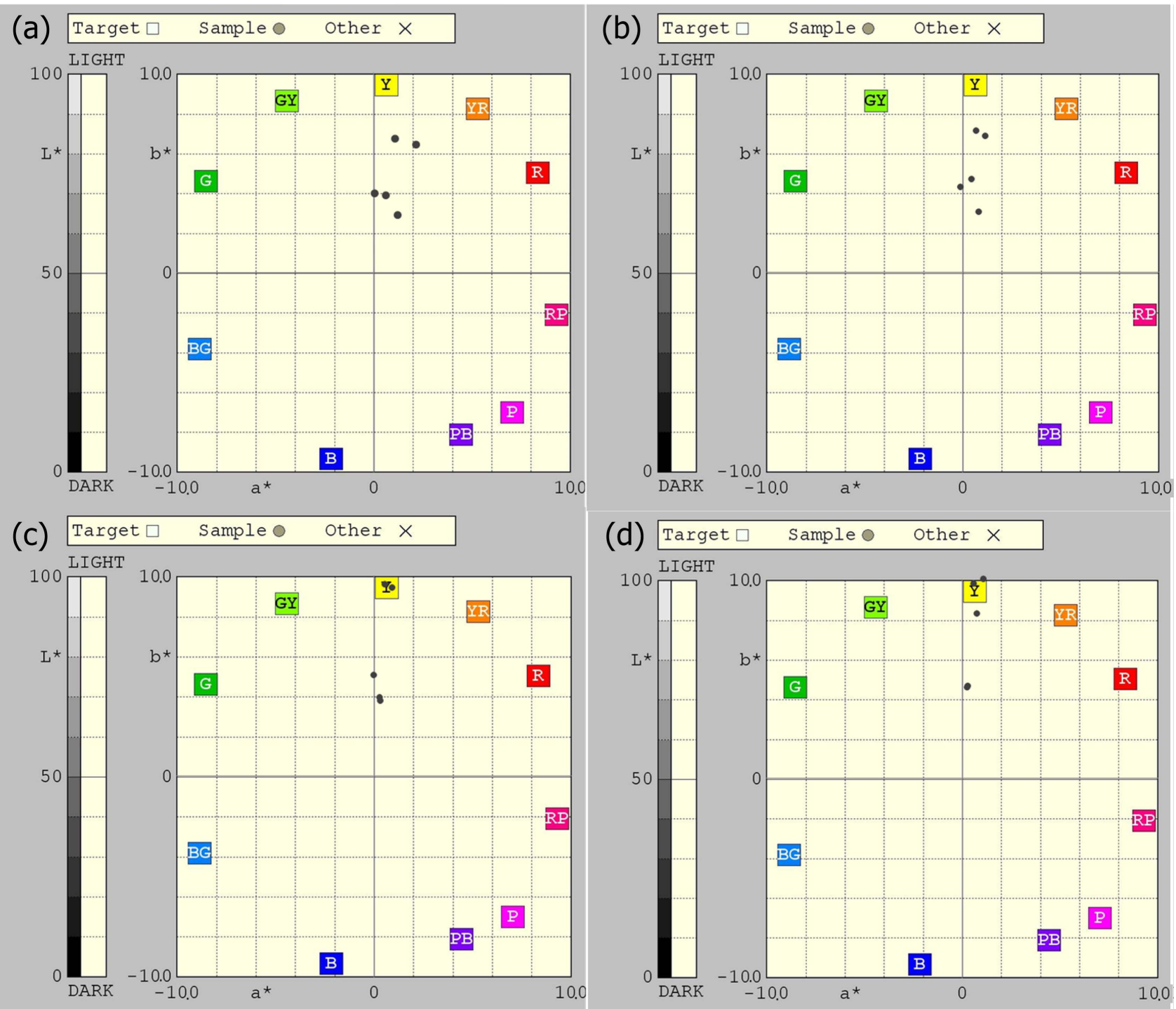

Fig. 11. Chromaticity values after oxidative sintering (a) at $1200^{\circ} \mathrm{C}$, (b) at $1250^{\circ} \mathrm{C}$; after reductive sintering (c) at $1200^{\circ} \mathrm{C},(\mathrm{d})$ at $1250^{\circ} \mathrm{C}$.

continuously increased beyond the sintering point, the whiteness is increased by the appearance of the glass phase.

The comparison of the color of the sintered bodies showed that the whiteness of the Korean kaolinite specimens (WA and PA) was lower than that of the imported kaolinite specimens (KM-85, LKC-60, KC-009) (Table 8 and Fig. 11). The comparison of the sintered bodies that were sintered in the oxidizing atmosphere at $1200^{\circ} \mathrm{C}$ and $1250^{\circ} \mathrm{C}$ showed that the $\mathrm{L}^{*}$ value, the whiteness factor, was higher in the imported kaolinite specimens (94\% to $97 \%$ ) than in the Korean kaolinite specimens (90\% to $92 \%)$. The same trend was found in the case of sintering in a reducing atmosphere (Table 8).

Table 9. Chromaticity Analysis Results (Sintered in Reductive Atmosphere)

\begin{tabular}{ccccccccccc}
\hline \multicolumn{1}{c}{$1200^{\circ} \mathrm{C}$ Sintering } \\
\hline $1200^{\circ} \mathrm{C}$ & KM-85 & LKC-60 & KC-009 & WA & PA & KM-85 & LKC-60 & KC-009 & WA & PA \\
$\mathrm{L}^{*}$ & 95.89 & 95.71 & 96.42 & 91.88 & 91.79 & 95.67 & 94.75 & 93.42 & 90.11 & 91.65 \\
$\mathrm{a}^{*}$ & 0.32 & 0.35 & -0.01 & 0.94 & 0.58 & 0.28 & 0.32 & 0.78 & 0.59 & 1.09 \\
$\mathrm{~b}^{*}$ & 3.91 & 3.75 & 5.01 & 9.36 & 9.55 & 4.56 & 4.62 & 8.27 & 9.78 & 10.42 \\
\hline
\end{tabular}




\section{Conclusions}

Stable quality of minerals is essential for stable quality of porcelain raw material (soji). However, the mineral resources used to prepare porcelain soji products, such as kaolin, have already been exhausted in Korea, and most of the raw materials are imported. Moreover, the soji products manufactured in Korea show a severe fluctuation in the quality in terms of the representative quality items such as water content, shrinkage rate, particle size, chromaticity, and composition. In the present study, several kaolinite minerals for porcelain soji products that are circulated in Korea were selected, and their properties as well as their quality as soji raw materials were analyzed. The Korean kaolinite had $\mathrm{SiO}_{2}$ and $\mathrm{Al}_{2} \mathrm{O}_{3}$ content lower than the theoretical values and included a relatively high ratio of feldspar containing as impurities of $\mathrm{Na}, \mathrm{K}$, and $\mathrm{Ca}$. This showed that the feldspar particles from anorthosite and granite that are less weathered remain in the Korean kaolinite. The high $\mathrm{CaO}$ content suggests the presence of anorthite. The iron content of the Korean kaolinite was generally about $1 \%$, which was higher than that of the Chinese or Vietnamese kaolinite specimens ( $0.5 \%$ or lower). Therefore, the whiteness of the Korean kaolinite was lower. An X-ray Rietveld quantitative analysis was performed to analyze the types and relative ratios of the crystal phases that are present in the raw material mineral. The results revealed that kaolinite and muscovite were the main phases in all the raw materials. The particle size analysis showed that the Korean kaolinite specimens (Seongju) contained more coarse particles having a diameter of $50 \mu \mathrm{m}$ or greater and showed a lower cumulative distribution of small particles having a diameter of $2 \mu \mathrm{m}$ or smaller in comparison with the Vietnamese or Chinese kaolinite specimens. The microstructure analysis showed that particle shape of the Vietnamese or Chinese kaolinite specimens was mostly (planar and needle-like). In the case of the Seongju kaolinite, the fine particles were planar but the coarse particles were in the shape of lumps similar to that of quartzite. The coarse particles may decrease the plasticity. The absorption rate was the lowest in the case of sintering in the reducing atmosphere at $1250^{\circ} \mathrm{C}$. The comparison of the chromaticity of the sintered bodies indicated that the whiteness of the Korean kaolinite specimens (Seongju) was lower than that of the imported kaolinite specimens. The whiteness of the sintered bodies that were sintered at $1200^{\circ} \mathrm{C}$ and $1250^{\circ} \mathrm{C}$ was also higher in the imported kaolinite specimens than in the Korean kaolinite specimens.

\section{Acknowledgments}

This work was supported by the Infrastructure Program for New Value Creation of the Traditional Ceramic Industry (BUS010025000), under the Ministry of Trade, Industry and Energy.

\section{REFERENCES}

1. W.-S. Cho, Infrastructure Program for New Value Creation of Traditional Ceramic Industry, Korea Institute of Ceramic Engineering and Technology, Icheon, 2011.

2. U. S. Kim, Investigation on the Deposit and Quality of Kaolinite in Hapcheon Province, Korea Institute of Ceramic Engineering and Technology, Icheon, 2014.

3. W.-S. Cho, Construction of Ceramicware Materials (Kaolinite) Database, Korea Institute of Ceramic Engineering and Technology, Icheon, 2016.

4. J. Kim, E. Heo, S.-J. Kim, and J.-Y. Kim, "Investigation of the Mineral Components of Porcelain Raw Material and their Phase Evolution during a Firing Process by Using a Rietveld Quantitative Analysis,” J. Korean Phys. Soc., 68 [1] 126-30 (2016).

5. A. Jeon, H. G. No, U. S. Kim, W. S. Cho, K. J. Kim, J. Y. Kim, C. M. Kim, C. S. Kim, and G. I. Kang. "Mossbauer Spectroscopic and Chromaticity Analysis on the Colorative Mechanism of Ancient Goryeo Celadon from Gangjin and Buan," Archaeometry, 56 [3] 392-405 (2012).

6. J.-Y. Kim, H. G. No, A. Jeon, U. S. Kim, J.-H. Pee, W. S. Cho, K. J. Kim, C. M. Kim, and C. S. Kim, 'Mossbauer Spectroscopic and Chromaticity Analysis on the Colorative Mechanism of Celadon Glaze," Ceram. Int., 37 [8] 3389-95 (2011).

7. J.-Y. Kim, H. G. No, A. Jeon, U. S. Kim, W.-S. Cho, K. J. Kim, C. M. Kim, and C. S. Kim, "Mossbauer Spectroscopic Study on Colorative Mechanism of Celadon Glaze," $J$. Korean Ceram. Soc., 48 [1] 34-9 (2011). 